\title{
Predators' consumption of unpalatable prey does not vary as a function of bitter taste perception
}

\author{
Liisa Hämäläinen, ${ }^{\mathrm{a}, \mathrm{b}, \bullet}$ Johanna Mappes, ${ }^{\mathrm{b}, \bullet}$ Rose Thorogood, ${ }^{\mathrm{a}, \mathrm{c}, \mathrm{d}, \bullet}$ Janne K. Valkonen, $, \mathrm{b}, \bullet$ \\ Kaijamari Karttunen, ${ }^{\mathrm{b}}$ Tuuli Salmi, ${ }^{\mathrm{b}}$ and Hannah M. Rowland ${ }^{\mathrm{a}, \mathrm{e}, \mathrm{f}, \mathrm{e}}$ \\ aDepartment of Zoology, University of Cambridge, Downing Street, CB2 3EJ Cambridge, UK, \\ bDepartment of Biological and Environmental Sciences, PO Box 35, University of Jyväskylä, 40014 \\ Jyväskylä, Finland, cHiLIFE Helsinki Institute of Life Science, PO Box 65, University of Helsinki, 00014 \\ Helsinki, Finland, dResearch Programme in Organismal \& Evolutionary Biology, Faculty of Biological \\ and Environmental Sciences, PO Box 65, University of Helsinki, 00014 Helsinki, Finland, eInstitute \\ of Zoology, Zoological Society of London, Regent's Park, NW1 4RY London, UK, and 'Max Planck \\ Institute for Chemical Ecology, Hans-Knöll-Straße 8, 07745, Jena, Germany
}

Received 28 June 2019; revised 29 October 2019; editorial decision 5 November 2019; accepted 12 November 2019; Advance Access publication 3 December 2019.

Many prey species contain defensive chemicals that are described as tasting bitter. Bitter taste perception is, therefore, assumed to be important when predators are learning about prey defenses. However, it is not known how individuals differ in their response to bitter taste, and how this influences their foraging decisions. We conducted taste perception assays in which wild-caught great tits (Parus major) were given water with increasing concentrations of bitter-tasting chloroquine diphosphate until they showed an aversive response to bitter taste. This response threshold was found to vary considerably among individuals, ranging from chloroquine concentrations of $0.01 \mathrm{mmol} / \mathrm{L}$ to $8 \mathrm{mmol} / \mathrm{L}$. We next investigated whether the response threshold influenced the consumption of defended prey during avoidance learning by presenting birds with novel palatable and defended prey in a random sequence until they refused to attack defended prey. We predicted that individuals with taste response thresholds at lower concentrations would consume fewer defended prey before rejecting them, but found that the response threshold had no effect on the birds' foraging choices. Instead, willingness to consume defended prey was influenced by the birds' body condition. This effect was age- and sex-dependent, with adult males attacking more of the defended prey when their body condition was poor, whereas body condition did not have an effect on the foraging choices of juveniles and females. Together, our results suggest that even though taste perception might be important for recognizing prey toxicity, other factors, such as predators' energetic state, drive the decisions to consume chemically defended prey.

Lay Summary: Individual differences in predators' bitter taste perception do not influence the consumption of chemically defended prey. Many prey species have bitter-tasting defenses that generate aversive responses in predators. We show that great tits vary in their response to bitter taste, but this does not influence the number of novel defended prey they attack during avoidance learning. This suggests that other factors, such as the current physiological state, have a larger impact on predators' foraging decisions.

Key words: aposematism, avoidance learning, bitter taste, chemical defense, great tits, toxins.

\section{INTRODUCTION}

Aposematic prey species have evolved diverse chemical defenses, including cardiac glycosides, alkaloids, and iridoid glycosides (Blum 1981), and often signal their defenses to predators with conspicuous warning colors (Poulton 1890; Ruxton et al. 2018). These chemical

Address correspondence to L. Hämäläinen. E-mail:1lh35@cam.ac.uk. defenses are often described as bitter tasting (Brower and Fink 1985; Glendinning 1994) and they typically generate aversive responses in predators, including head shaking, bill/mouth cleaning, and spitting out of food. Avian predators learn to avoid aposematic prey based on bitter taste (e.g., Skelhorn and Rowe 2006; Skelhorn and Rowe 2010) and birds' responses to bitter tastes can also provide other predators with social information about prey quality Johnston et al. 1998; Skelhorn 2011; Thorogood et al. 2018; 
Hämäläinen et al. 2019a). Bitter taste perception is therefore assumed to be important when predators are gathering information about prey profitability.

How predators respond to chemically defended prey, however, varies among predator species (Endler and Mappes 2004). Some species may, for example, be more resistant to prey toxins and consume chemically defended prey that are unpalatable and toxic to other predators (Fink et al. 1983; Brodie and Brodie 1990; Glendinning et al. 1990). Some predator species have also evolved apparently taste-guided behaviors to overcome chemical defenses, with examples including black-backed orioles, black-headed grosbeaks, and some Australian raptors that dissect prey and consume only body parts that contain the least toxins (Calvert et al. 1979; Fink and Brower 1981; Beckmann and Shine 2011). Individual predators of the same species can also vary in their ability or motivation to discriminate between defended prey (Halpin et al. 2012), but the reasons for such individual differences are poorly understood.

In humans, individual differences in taste perception, linked to genetic polymorphisms in bitter taste receptors (Tas2rs - Chandrashekar et al. 2000; Lindemann 2001; Behrens and Meyerhof 2013), affect food choice and dietary habits (Garcia-Bailo et al. 2009; Lipchock et al. 2017). There is now growing molecular evidence for the potential for variation in taste perception in birds, both between (Behrens et al. 2014; Wang and Zhao 2015; Zhao et al. 2015) and within species (Davis et al. 2010; Su et al. 2016). For example, Su et al. (2016) detected 3-13 short nucleotide polymorphisms (SNPs) in the family of G-protein-coupled receptors responsible for bitter taste perception in Sichuan domestic and Tibetan chicken populations. Genetic variation in bitter taste is also reported in white-throated sparrows (Davis et al. 2010). Whether individual differences in bitter taste perception influence the food choice of avian predators, however, has so far not been tested experimentally.

Although taste may be important for discriminative learning, predators' decisions to consume chemically defended prey may also be shaped by other factors, such as their physiological state (Sherratt 2003; Sandre et al. 2010; Skelhorn et al. 2016). Rather than avoiding all chemically defended prey, predators are assumed to make statedependent decisions to include toxic prey in their diet when the benefits of gaining nutrients outweigh the costs of ingesting toxins (Skelhorn et al. 2016; Marples et al. 2018). For example, European starlings consume more chemically defended prey when their body mass and fat stores are reduced (Barnett et al. 2007; Barnett et al. 2012), or when their energetic needs are higher because of lower ambient temperature (Chatelain et al. 2013). Willingness to consume chemically defended prey may also depend on predators' previous consumption of toxins (Skelhorn and Rowe 2007) or the nutrient content of the defended prey (Halpin et al. 2014), and it is possible that these physiological factors have a greater influence than bitter taste perception on predators' foraging decisions. Therefore, our aim was to test whether predators' bitter taste perception influences the consumption of chemically defended prey, or whether foraging decisions are driven more by predators' physiological measures.

We investigated bitter taste perception and avoidance learning in wild-caught great tits (Parus major). Great tits are generalist predators and during the summer their diet consists mainly of insects and other invertebrates (Naef-Daenzer et al. 2000), so they are likely to encounter chemically defended prey (Majerus and Majerus 1997). We first tested whether individuals differed in their response to bitter-tasting chloroquine diphosphate solution. In the taste perception assays, birds were offered solutions with increasing concentrations of chloroquine until they showed an aversive response to bitter taste. The test was repeated on the following day to investigate the repeatability of individuals' responses. We then investigated avoidance learning by the same birds by presenting them with a random sequence of novel palatable and defended prey until they refused to attack defended prey. We predicted that individuals that displayed aversion at lower concentrations (i.e., had lower taste response thresholds) would consume fewer defended prey before rejecting them. If so, variation in bitter taste perception might introduce more heterogeneity in the predator population and create varying predation pressures for aposematic prey, therefore influencing the selection for prey defenses and signaling (Endler and Mappes 2004).

\section{METHODS}

\section{Study species}

The experiment was carried out at the Konnevesi Research Station in Central Finland during the winter of 2014-2015. Great tits ( $n=59 ; 19$ juvenile and 8 adult females, and 16 juvenile and 16 adult males) were captured from a feeding site, kept in captivity for approximately 1 week for testing, and then released back to the capture site. Birds were housed individually in plywood cages $(80 \times$ $65 \times 50 \mathrm{~cm}$ ) with a daily light period of $12.5 \mathrm{~h}$. Sunflower seeds, peanuts, tallow, and fresh water were provided ad libitum, except prior and during the experiments when food or water restriction was necessary to motivate foraging or drinking. We recorded sex and age of the individuals based on their plumage, and measured their tarsus length $(0.01 \mathrm{~cm})$. Birds were also weighed $(0.25 \mathrm{~g})$ both after capture and before release. Before release, all individuals were ringed for identification purposes.

\section{Response to bitter taste}

Bitter-tasting solutions were prepared by mixing chloroquine diphosphate salt with water to produce ten different concentrations (mmol/L) $0.01 ; 0.05 ; 0.10 ; 0.50 ; 0.75 ; 1.0 ; 2.0 ; 3.0 ; 5.0 ; 8.0$. Taste assays were conducted in a $50 \times 66 \times 49 \mathrm{~cm}$ sized plywood cage that had a front wall made of plexiglass, enabling us to observe and film the birds during the assays. Birds were moved to the test cages in the morning to start the taste assays. To increase their motivation to drink, we moved birds before the automated light in their home cages turned on (birds did not have light during the night) which ensured that they did not drink in their home cages before the assays. Birds, therefore, did not have access to fresh water before they were presented with the first test solution, and during the assays they only had access to test solutions. Food was always freely available.

Birds were first presented with a white drinking bottle containing fresh water (Figure la). After presenting a bottle, we waited for the bird to drink and recorded its response with a video camera (Canon Legria HF R37). If the bird did not drink in $15 \mathrm{~min}$, we removed the bottle for at least $15 \mathrm{~min}$ (waiting for motivation to increase) before offering the same bottle again. This was repeated until the bird drank from the bottle. We then removed the bottle and waited for 15 min before presenting the bird with a bottle containing the lowest concentration of chloroquine diphosphate solution. This procedure continued, the bird being presented with solutions of increasing concentration, until we observed a first aversive response, defined as head shaking, bill-wiping, and/or spitting out of the solution (Supplementary Video). Our criterion for the response threshold included any of these responses, rather than a bird performing all three behaviors. One of the main functions of bill-wiping is to clean the beak (Cuthill et al. 1992), and some birds performed a couple of bill 
(a)

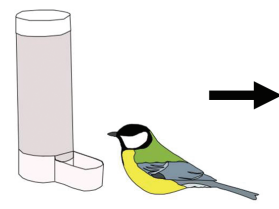

$0 \mathrm{mmol} / \mathrm{l}$

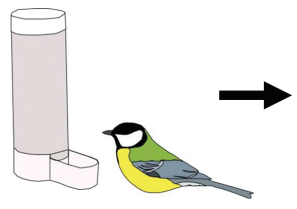

$0.01 \mathrm{mmol} / 1$

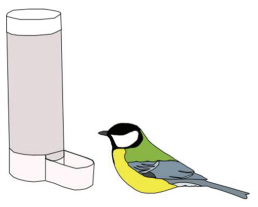

$0.05 \mathrm{mmol} / 1$

(b)
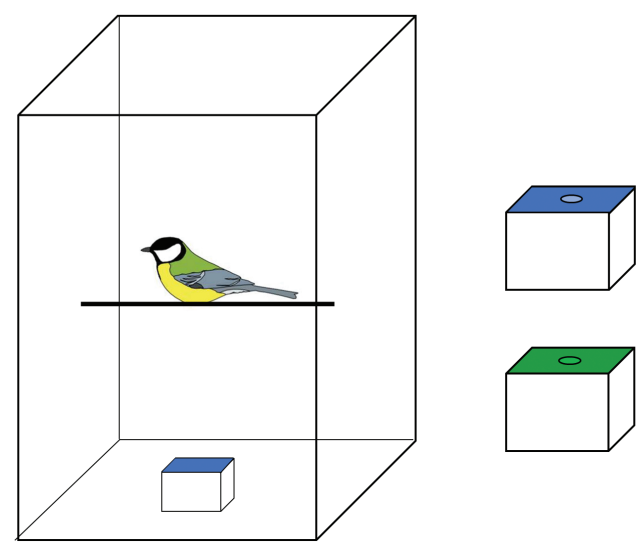

Figure 1

Experimental set-up. (a) We first conducted taste assays where birds $(n=59)$ were given water with increasing concentration of chloroquine diphosphate until they showed an aversive response to bitter taste. (b) We then investigated how many defended prey birds $(n=56)$ consumed before rejecting them by presenting birds with novel palatable and defended prey. Prey items were mealworm pieces that were presented to birds in small plastic cups that were placed on the colored cube.

wipes after drinking only fresh water. However, these responses were much weaker than the aversive responses to the chloroquine solutions. Other behaviors (head shaking and spitting out of the solution) were never observed when birds were offered fresh water. The taste assay was finished after birds showed the first aversive response.

We weighed each drinking bottle before and after presentation to calculate the total amount of solution $(\mathrm{mL})$ and chloroquine (mmol) that birds consumed. This was important because, although all individuals were similarly water-deprived before the test, birds differed in the amount of solution they drank from each bottle. To investigate the repeatability of individual responses, 54 of 59 individuals were tested twice over two sequential days, with both tests following the same protocol. In the beginning of the experiment, we did not repeat the test with all individuals, therefore, five birds were tested only once.

\section{Avoidance of defended prey}

After the taste assays, we tested how many novel chemically defended prey items each bird consumed before they rejected them. The avoidance learning test was conducted in the same test cages as taste assays. Prey items were chopped mealworm (Tenebrio molitor) pieces (approximately $0.5 \mathrm{~g}$ ). These were presented to birds in small plastic cups $(0.5 \mathrm{~mL})$ that contained either water (palatable prey) or $65 \mathrm{mmol} / \mathrm{L}$ chloroquine solution (defended prey). Our pilot tests indicated that birds did not learn to avoid defended prey with lower doses of chloroquine, possibly due to the low costs of consuming small quantities of toxins. We, therefore, chose a $65 \mathrm{mmol} / \mathrm{L}$ concentration, even though it was considerably higher than the taste response thresholds in the taste assays (see Results). To make palatable and defended prey visually distinct, we colored the solution by adding either green or blue food dye, and placed the cup on Styrofoam cubes of the same color $\left(10 \mathrm{~cm}^{3}\right.$; Figure 1b). We counterbalanced the color associated with unpalatability (blue palatable, green defended, $n=29$; reversed, $n=27$ ). Three birds (one juvenile female, and one juvenile and one adult male) did not participate in the avoidance learning test, because they refused to attack any prey $(n=56)$.

Before the test birds were trained to eat mealworm pieces from a cup that contained water and was presented on a white Styrofoam cube. We then tested each bird's initial color preference by presenting them simultaneously with blue and green prey items that were both palatable, and recording which prey birds attacked first. Each bird was tested two times, alternating which prey item was on the left and which on the right side of the cage. All birds, therefore, had positive experience of both colors before the avoidance learning test. We analyzed birds' preferences using a generalized linear mixed effects model (GLMM) with a binomial error distribution (logit link). The model included the order in which prey items were consumed as a response variable, prey color as an explanatory variable and bird identity as a random effect. We found that birds had a slight preference for green (estimate $=-0.575 \pm 0.270$, $\mathrm{Z}=-2.131, P=0.03$ ), with $59 \%$ of the individuals (33/56 birds) attacking the green prey first in the first preference test and $55 \%$ (31/56 birds) in the second preference test.

In the avoidance learning test, palatable and defended prey items were presented to the birds sequentially in blocks of six (three palatable and three defended prey). Other food was restricted $90 \mathrm{~min}$ prior to the test and blocks always started with a palatable prey item to ensure that the bird was motivated to forage. The following five prey items were presented in a randomized order and birds were given 5 min to attack each prey. If they attacked the prey within this time, they were allowed to eat it before the next prey was presented. After the bird had attacked all six prey items in the block, we paused for $10 \mathrm{~min}$ before beginning the next block (next six prey items). Blocks 
continued until the birds refused to attack two consecutive defended prey items (within $5 \mathrm{~min}$ ) but still continued to eat palatable prey presented immediately after a defended prey, indicating that they had learned to recognize and avoid defended prey. However, if birds refused to attack the palatable prey (within $5 \mathrm{~min}$ ), we concluded that they had not learned to discriminate between prey items but instead were not motivated to attack any prey. In this case, testing paused for at least $10 \mathrm{~min}$ before recommencing. To measure how fast birds learned to discriminate between prey, we recorded the number of defended prey attacked before birds reached the learning criterion.

\section{Statistical analyses}

We first calculated individuals' body condition index to investigate whether physiological state influenced the birds' behavior in the experiments. Body condition index was calculated based on tarsus and weight measures, following the method described by Peig and Green (2009). We used a weight measure that was taken after birds were captured from the wild. However, calculating body condition based on the weight at the release did not change any of the results. Because body condition had a different effect on avoidance learning in juveniles and adults, and in males and females (see Results), we also investigated whether body condition measures differed between the age and sex groups. This was done using a generalized linear model where body condition was modeled as a function of birds' age and sex.

We tested whether birds' sex, age, or body condition influenced their probability to respond to a chloroquine solution using a GLMM with a binomial error distribution (using lme4 package; Bates et al. 2015). Taste response thresholds (concentrations at which birds showed the first aversive response) were first converted to integers by multiplying them by 100 , and then used as a bound response variable, together with the probability of showing an aversive response (i.e., 1). Explanatory variables in the model included birds' sex, age, body condition index and test day (first/second taste assay), as well as bird identity as a random effect. We started model selection with a model that included all possible two-way interactions between sex, age, and body condition, and removed the interaction terms based on their significance (see Supplementary Material for model selection). Because consumption varied among individuals, we also calculated the total amount of chloroquine diphosphate consumed before the first aversive response, and conducted the same analysis using this measure (mmol, converted to integers) as a bound response variable, instead of the threshold concentration. To investigate the consistency of birds' responses in the two taste assays, we calculated the repeatability in the taste response thresholds between the assays by estimating which proportion of the observed variance in the response thresholds was attributed to bird identity. This was calculated from a GLMM with a binomial error distribution, using the $r p t R$ package (Stoffel et al. 2017). Bird identity was included as a random effect in the model.

We next investigated how chloroquine concentration influenced the volume of test solution consumed, and whether this depended on the test day (first/second taste assay). We used a GLMM with a negative binomial error distribution, as the data were right-skewed. The volumes of solution consumed $(\mathrm{mL})$ were converted to integers and used as a response variable, and explanatory variables included an interaction between chloroquine concentration (continuous variable) and test day, and birds' sex, age and body condition as fixed effects, and bird identity as a random effect. Because most birds responded to concentrations between 0.01 and $0.5 \mathrm{mmol} / \mathrm{L}$ (Figure 2), we did not include higher concentrations in our analysis. We further investigated whether consumption decreased when birds were presented the first chloroquine solution using a paired sample $t$-test where the consumption of fresh water $(0 \mathrm{mmol} / \mathrm{L})$ and the first chloroquine solution $(0.01 \mathrm{mmol} / \mathrm{L})$ were compared.

To investigate the relationship between taste perception and avoidance learning, we used a generalized linear model with a Poisson error

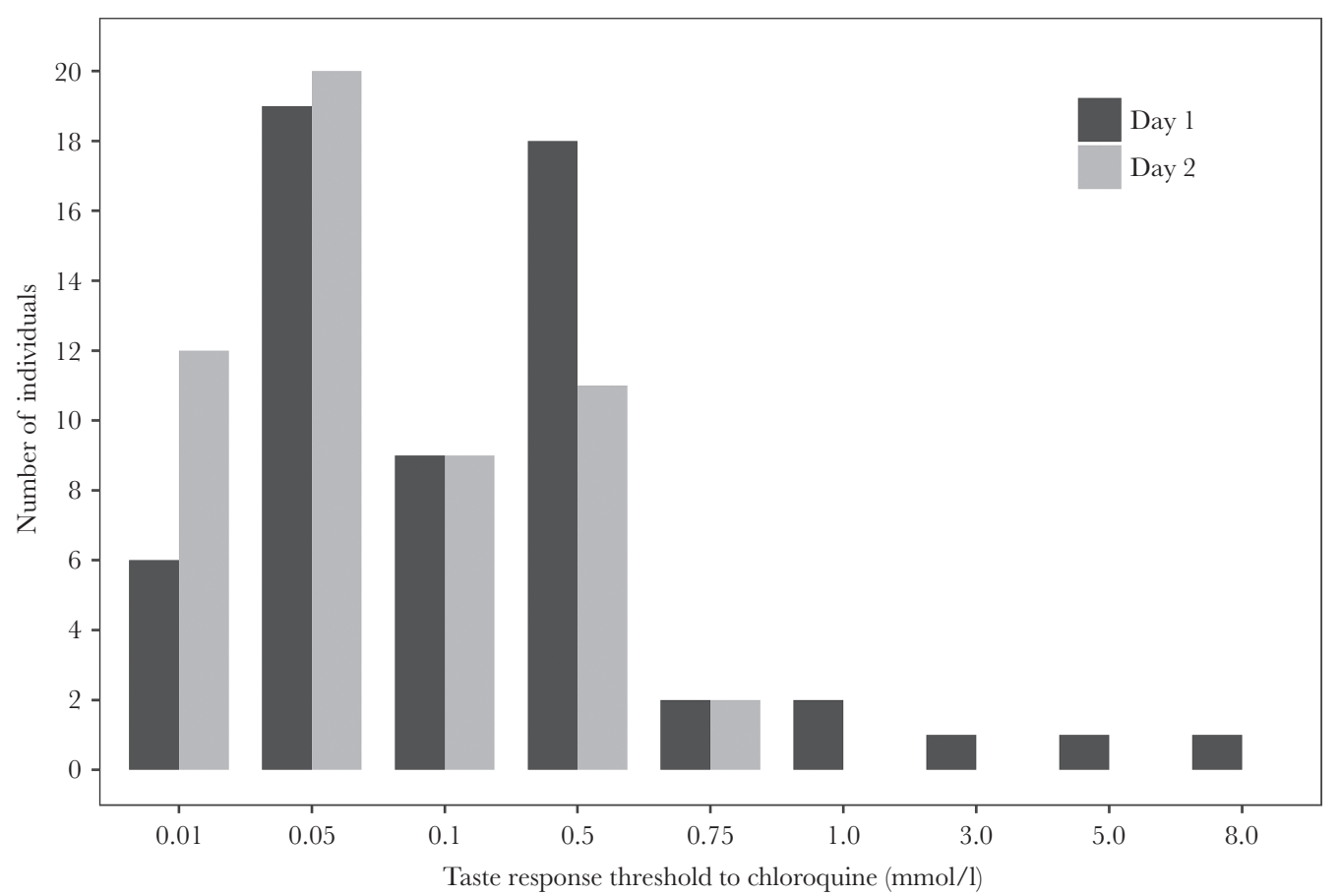

Figure 2

Individual variation in bitter taste response thresholds $(\mathrm{mmol} / \mathrm{L})$ in the first (day 1; dark gray bars; $n=59)$ and second taste assay (day 2; light gray bars; $n=54)$. 
distribution. The number of defended prey attacked before avoidance was used as a response variable, and explanatory variables included possible two-way interactions between birds' taste response threshold (in the first taste assay), sex, age, and body condition index. We removed interaction terms from the model based on the significance of the terms (see Supplementary Material for model selection). Because birds showed an initial preference for green, the color that signaled defended prey (green/blue) was included as a covariate in all models. Finally, we investigated whether the amount of chloroquine consumed 1) during the first taste assay, or 2) in total during both taste assays influenced the number of defended prey attacked before avoidance by conducting the same analysis using the amount of chloroquine consumed as an explanatory variable, instead of the taste response threshold. Seven individuals (two juvenile and one adult females, and four adult males) did not have a body condition measure (we did not measure birds' tarsus length in the beginning of the experiment) and they were therefore excluded from the relevant analyses. In addition, we excluded one bird that had a considerably higher body condition index than others (body condition $=22.3$ ), as this was likely due to an error in tarsus measurement. All analyses were conducted using $\mathrm{R}$ version 3.6.0 (R Core Team 2019).

\section{RESULTS}

\section{Response to bitter taste}

The concentration at which birds first showed an aversive response varied considerably between individuals, ranging from $0.01 \mathrm{mmol} / \mathrm{L}$ to $8.0 \mathrm{mmol} / \mathrm{L}$ in the first taste assay, and from $0.01 \mathrm{mmol} / \mathrm{L}$ to $0.75 \mathrm{mmol} / \mathrm{L}$ in the second taste assay (Figure 2). The repeatability in birds' responses in the two taste assays was relatively low: $R=0.13$ (95\% CI: 0.02-0.13). There was a significant difference between the two taste assays, with birds reacting to lower concentrations during the second assay (Table 1). We found that juveniles responded at lower concentrations than adults (adults versus juveniles: estimate $=0.808 \pm 0.367, Z=2.200, P=0.03)$, and males at lower concentrations than females (females versus males: estimate $=0.714 \pm 0.352, \mathrm{Z}=2.030, P=0.04)$. However, these effects were driven by one adult female that reacted at a much higher concentration than other birds $(8 \mathrm{mmol} / \mathrm{L})$; when this individual was excluded from the analysis, the effects of sex and age were no longer significant at alpha level 0.05 (Table 1). Body condition did not influence birds' response and this result did not change when the outlier was excluded from the analysis (Table 1). Because birds varied in the amount of solution consumed, we also tested whether birds' sex, age or body condition predicted the total amount of chloroquine consumed before the first aversive response, but none of these effects was significant (see Supplementary Material for the full results). However, we found that birds responded to a smaller amount of chloroquine in the second taste assay than the first (effect of test day: estimate $=0.718 \pm 0.227, Z=3.165, P=0.002$; Supplementary Material).

Birds consumed less solution as the concentration of chloroquine diphosphate increased (Table 2; Figure 3). This effect was the same on both test days (concentration $\times$ test day: estimate $=0.158 \pm$ $0.509, Z=0.310, P=0.76$ ), and we therefore removed the interaction between chloroquine concentration and test day from the final model. The volume of solution consumed did not depend on birds' age, sex, or body condition, but individuals consumed less of the solutions on the second day (Table 2), with the most noticeable decrease in the consumption of fresh water $(0 \mathrm{mmol} / \mathrm{L}$; Figure 3$)$. We also found that in the first taste assay (day 1 ) the consumption of test solution decreased significantly between the first $(0 \mathrm{mmol} / \mathrm{L})$ and second $(0.01 \mathrm{mmol} / \mathrm{L})$ test solution (paired samples $t$-test: $t=6.833$, $\mathrm{df}=56, P<0.001)$, whereas this difference was not observed on the second day (paired samples $t$-test: $t=1.564$, $\mathrm{df}=52, P=0.12$ ).

\section{Avoidance of defended prey}

Contrary to our prediction, birds' bitter taste threshold did not influence the number of defended prey that they attacked during avoidance learning (Table 3). Similarly, the color that signaled unpalatability (blue/green) did not influence avoidance learning (Table 3). Instead, we found significant interactions between age and body condition index (Figure 4a), and sex and body condition index (Table 3; Figure 4b). Because there was no significant threeway interaction between these variables (sex $\times$ age $\times$ body condition: estimate $=0.224 \pm 0.167, Z=-1.343, P=0.18$ ), we next investigated each interaction separately by conducting two models that included only an interaction between age and body condition, or sex and body condition.

We found that adult birds attacked more of the defended prey when their body condition index was low (estimate $=-0.274 \pm 0.060$, $Z=-4.545, P<0.001$ ), whereas body condition did not have a significant effect on the foraging choices of juveniles (estimate $=0.088 \pm$ $0.060, z=1.472, P=0.14$; Figure 4a). We also found that males in poorer body condition attacked more of the defended prey (estimate $=-0.210 \pm 0.056, Z=-3.743, P<0.001$ ), in contrast to females that did not attack defended prey as a function of their body condition (estimate $=0.032 \pm 0.058, Z=0.550, P=0.58$; Figure $4 \mathrm{~b})$. However, the number of birds in each age and sex category was also not equal (adult females: $n=6$; adult males: $n=12$; juvenile females: $n=15$; juvenile males: $n=15$ ). Body condition measures did not differ between the age (adults versus juveniles: estimate $=0.284 \pm$ $0.374, Z=0.761, P=0.45$ ) or sex categories (females versus males:

Table 1

Best-fit generalized linear mixed effects model explaining the variation in the taste response thresholds among individuals $(n=50)$

\begin{tabular}{lrrr} 
Terms in the model & Estimate & SE & $Z$ \\
\hline Intercept & -3.100 & 2.551 & -1.215 \\
Sex (male) & 0.543 & 0.338 & 1.606 \\
Age (juvenile) & 0.613 & 0.355 & 1.727 \\
Body condition & -0.029 & 0.138 & -0.211 \\
Test day (second taste assay) & 0.469 & 0.230 & 2.042
\end{tabular}

The probability that birds responded to the test solution (within chloroquine concentration unit) was included as a response variable. Explanatory variables in the best-fit model included birds' age, sex, and body condition index, as well as test day (first/second taste assay). Bird identity was included as a random effect (variance $=0.708$ ). Intercept gives the probability for adult females showing an aversive response in the first taste assay (day 1 ). One bird that responded at much higher concentration than others $(8 \mathrm{mmol} / \mathrm{L})$ was excluded from the analysis. 
Table 2

Best-fit generalized linear mixed effects model explaining the volume of test solution that birds $(n=51)$ consumed during the first five chloroquine concentrations

\begin{tabular}{|c|c|c|c|c|}
\hline Terms in the model & Estimate & $\mathrm{SE}$ & z & $P$ \\
\hline Intercept & 7.674 & 0.694 & 11.057 & $<0.001$ \\
\hline Sex (male) & 0.034 & 0.091 & 0.372 & 0.71 \\
\hline Age (juvenile) & -0.019 & 0.094 & -0.202 & 0.84 \\
\hline Body condition & 0.022 & 0.037 & 0.574 & 0.57 \\
\hline Chloroquine concentration & -2.087 & 0.247 & -8.439 & $<0.001$ \\
\hline Test day (second taste assay) & -0.264 & 0.071 & -3.703 & $<0.001$ \\
\hline
\end{tabular}

Explanatory variables in the best-fit model included birds' age, sex, and body condition index, as well as chloroquine concentration and test day (first/second taste assay). Bird identity was included as a random effect (variance $=0.04)$. Intercept gives the estimate for the volume of the first test solution $(0 \mathrm{mmol} / \mathrm{L})$ that adult females consumed in the first taste assay (day 1).

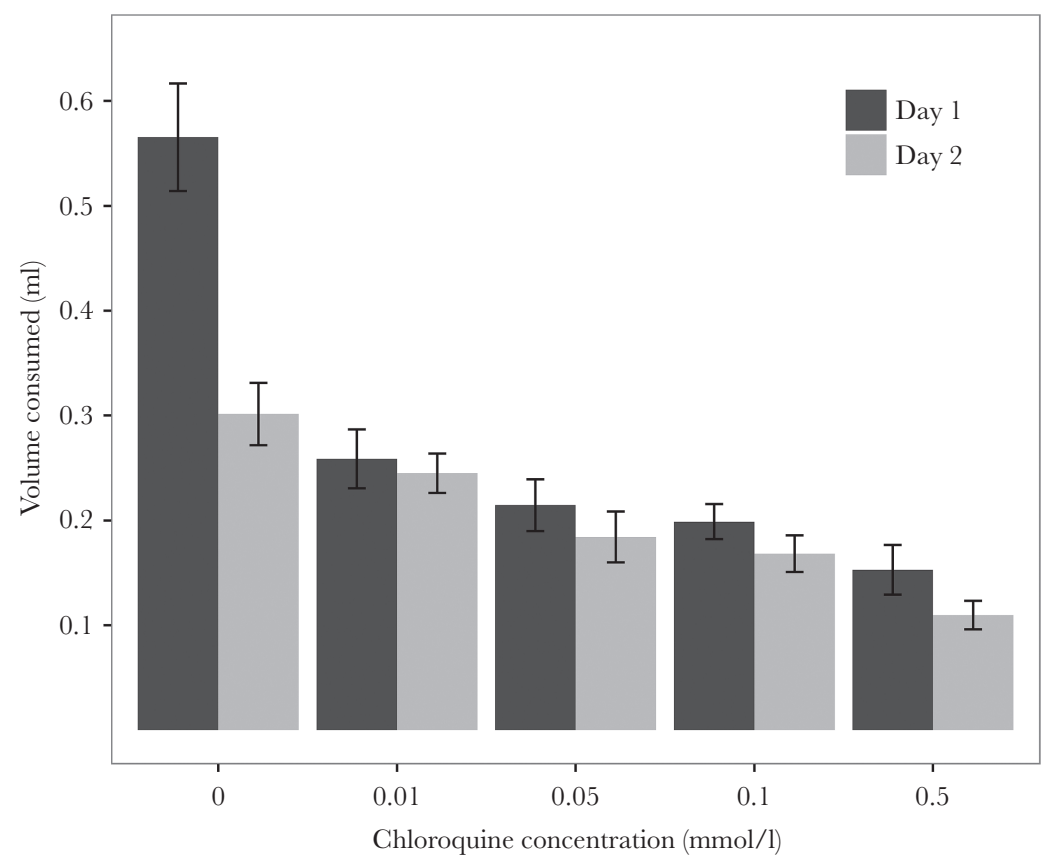

Figure 3

Mean ( \pm SE) volume of test solutions that birds consumed at each chloroquine concentration in the first (day 1; dark gray bars) and second taste assay (day 2; light gray bars). Because the test was finished when an individual responded to bitter taste, the number of observations at each concentration varies from 59 (0 mmol/L; day 1) to 11 (0.5 mmol/L; day 2$)$.

estimate $=-0.076 \pm 0.361, Z=-0.209, P=0.84)$. A bird that responded only at the $8 \mathrm{mmol} / \mathrm{L}$ concentration in the first taste assay was excluded from the analysis (final $n=48$ ), as it was a clear outlier and had a disproportionate effect on the results (see Supplementary Material for the model including this individual). Finally, we conducted similar models to test whether the amount of chloroquine consumed during taste assays influenced avoidance learning, but found no evidence that the amount of chloroquine consumed during the first taste assay (estimate $=55.364 \pm 208.180, Z=0.266, P=0.79$ ) or in total during two taste assays (estimate $=20.847 \pm 165.584$, $Z=0.126, P=0.90)$ influenced the consumption of defended prey (see Supplementary Material for the full results).

\section{DISCUSSION}

Our study demonstrates that wild predators can differ greatly in their response to bitter compounds that are structurally related to real prey defenses. We found two orders of magnitude difference in the concentration at which great tits responded to chloroquine, which is in line with the results of Warren and Vince (1963), who also found individual variation in great tits' responses to bittertasting solutions. Contrary to our prediction, taste response did not correlate with the number of defended prey items consumed in a later avoidance learning test. Instead, we found that adult males attacked more defended prey when their body condition index was low. This supports the idea that individuals can strategically consume defended prey when their energetic needs are higher (Sherratt 2003; Barnett et al. 2007, 2012; Skelhorn et al. 2016; Marples et al. 2018), although this may be age- and sex-dependent. It also indicates that even though bitter taste perception may be important in detecting toxic prey (Skelhorn and Rowe 2010), other factors, such as physiological state, have a larger influence on predators' foraging decisions.

Predators' reactions to chemically defended prey can vary within and between species (Exnerová et al. 2003; Endler and Mappes 2004). We found high individual variability in great tits' responses to bitter taste, with the taste response threshold varying from chloroquine concentrations of $0.01 \mathrm{mmol} / \mathrm{L}$ to $8 \mathrm{mmol} / \mathrm{L}$. Previous 
Table 3

Best-fit generalized linear model explaining the number of defended prey that birds $(n=48)$ attacked during avoidance learning

\begin{tabular}{|c|c|c|c|c|}
\hline Terms in the model & Estimate & $\mathrm{SE}$ & $z$ & $P$ \\
\hline Intercept & 4.991 & 1.368 & 3.648 & $<0.001$ \\
\hline Taste threshold & 0.078 & 0.101 & 0.774 & 0.44 \\
\hline Sex (male) & 4.318 & 1.445 & 2.989 & 0.003 \\
\hline Age (juvenile) & -6.602 & 1.566 & -4.215 & $<0.001$ \\
\hline Body condition & -0.151 & 0.074 & -2.025 & 0.04 \\
\hline Defended prey color (green) & 0.060 & 0.099 & 0.602 & 0.55 \\
\hline Body condition * Age (juvenile) & 0.348 & 0.085 & 4.086 & $<0.001$ \\
\hline Body condition * Sex (male) & -0.226 & 0.078 & -2.885 & 0.004 \\
\hline
\end{tabular}

Explanatory variables in the best-fit model included interactions between age and body condition index, and sex and body condition index, as well as taste response threshold in the first taste assay $(\mathrm{mmol} / \mathrm{l})$ and the color of defended prey (green/blue). Intercept gives the estimate for the number of defended prey that adult females attacked when defended prey were blue. One bird that responded at much higher concentration than others $(8 \mathrm{mmol} / \mathrm{L})$ was excluded from the analysis.

studies in humans indicate that bitter taste sensitivity might decline with age (Cowart et al. 1994; Fukunaga et al. 2005), but the evidence of the effects of aging on taste in other animals is scarce (but see Shin et al. 2012). We found some evidence that juveniles responded to lower bitter taste concentrations than adults, but this effect seemed to be driven by three adult birds that had high taste response thresholds $(3,5$, and $8 \mathrm{mmol} / \mathrm{L})$. It is possible that these individuals were significantly older than other adult birds in our study, which could explain their lower taste sensitivity, but we do not have more accurate records of their age and cannot verify this. We also found no evidence that sex or body condition influenced taste responses, indicating that the observed differences might be genetically determined. In humans, polymorphism in bitter taste receptor genes affects the ability to sense the intensity of bitterness, as exemplified by the gene variants of TAS2R38 and sensitivity to phenylthiocarbamide (PTG) and propylthiouracil (PROP; Bufe et al. 2005). The varied perception of quinine intensity is also associated with genetic variants in human TAS2r19 genes (Reed et al. 2010). Although genetic variants in bitter taste receptor genes has been demonstrated in chickens (Su et al. 2016) these have not yet been linked to taste behavior. While we did not genotype our individual great tits, we hypothesize that similar variation is likely to be found, though one or more bitter receptor or salivary proline-rich protein genes, or receptor expression levels could be responsible for the observed differences (Lipchock et al. 2013), and this warrants further investigation.

Determining taste sensitivity thresholds in animals is challenging (Rowland et al. 2015). A common method is to use twobottle choice tests in which individuals are given a choice of test solution and pure water, and the consumption of the solutions is compared (e.g., Warren and Vince 1963; Matson et al. 2004). In our experiment, we investigated when birds showed a first behavioral response to bitter-tasting solutions. Rather than testing taste detection, our experiment, therefore, measured the threshold to respond to bitter taste, and it is possible that individuals were able to detect chloroquine at lower concentrations. In support of this idea, we found that birds decreased their consumption behavior significantly between $0 \mathrm{mmol} / \mathrm{L}$ and $0.01 \mathrm{mmol} / \mathrm{L}$, indicating that they might have already detected the lowest concentration of chloroquine. However, it is also possible that birds were simply thirstier in the beginning of the experiment. To disentangle whether the decrease in consumption was due to birds detecting chloroquine or being less thirsty, we would need a control group that receives only water at each step. In our study, individuals also varied in the volume of solution they drank, which might have influenced their aversive responses, and further studies should aim to control this by presenting birds with set amounts of chloroquine solution. Furthermore, our results suggest that previous experience may influence how birds respond to bitter taste. We aimed to minimize any effects of learning during the assays, but the lower taste response thresholds in the second taste assay indicate that the birds did learn to associate drinking bottles with some post-ingestive consequences of consuming chloroquine during the first day. This is further supported by our finding of the birds decreasing their consumption of fresh water from the first to the second assay, which indicates that they were more hesitant to drink during the second day. The consumption of other test solutions tended to similarly decrease between the assays, but because their consumption was already low on the first day, this decrease was less prominent compared to fresh water (Figure 3).

Variability in bitter taste sensitivity can influence food choice in humans (Garcia-Bailo et al. 2009; Lipchock et al. 2017), but whether it affects predators' decisions to attack chemically defended prey has until now not been tested. We did not find evidence that birds' bitter taste response threshold influenced the consumption of defended prey during the avoidance learning test. Instead, birds' physiological state seemed to affect their foraging behavior, with adult males attacking more defended prey when their body condition was poor. This is consistent with previous work showing that starlings are more likely to attack defended prey when their body mass and fat stores are experimentally reduced (Barnett et al. 2007, 2012), supporting the idea that educated predators attack toxic prey depending on nutrient-toxin trade-offs (Skelhorn et al. 2016). Indeed, our experiment might have measured birds' willingness to consume defended prey, rather than how well they learned to discriminate the prey items, as birds only had a choice to attack or reject defended prey with no alternative prey present. Giving birds a simultaneous choice between palatable and defended prey, or comparing hesitation times to attack each prey type might, therefore, provide better estimates of discriminative learning. Studies in a more complex foraging environment with palatable and defended prey (e.g., in the "novel world," Alatalo and Mappes 1996) would also allow us to investigate the effects of variation in predator taste sensitivity on the mortality of defended prey, and how this influences the evolution of prey defenses. For example, prey might evolve higher levels of chemical defense and reduced visual conspicuousness when the predator community consists of less sensitive predators, although this is likely to depend on the costs to prey of producing chemical defenses (Longson and Joss 2006). Similar to other intra- and interspecific variation among predators (Endler and Mappes 2004), variation in taste sensitivity might, therefore, have important consequences for prey, but further 

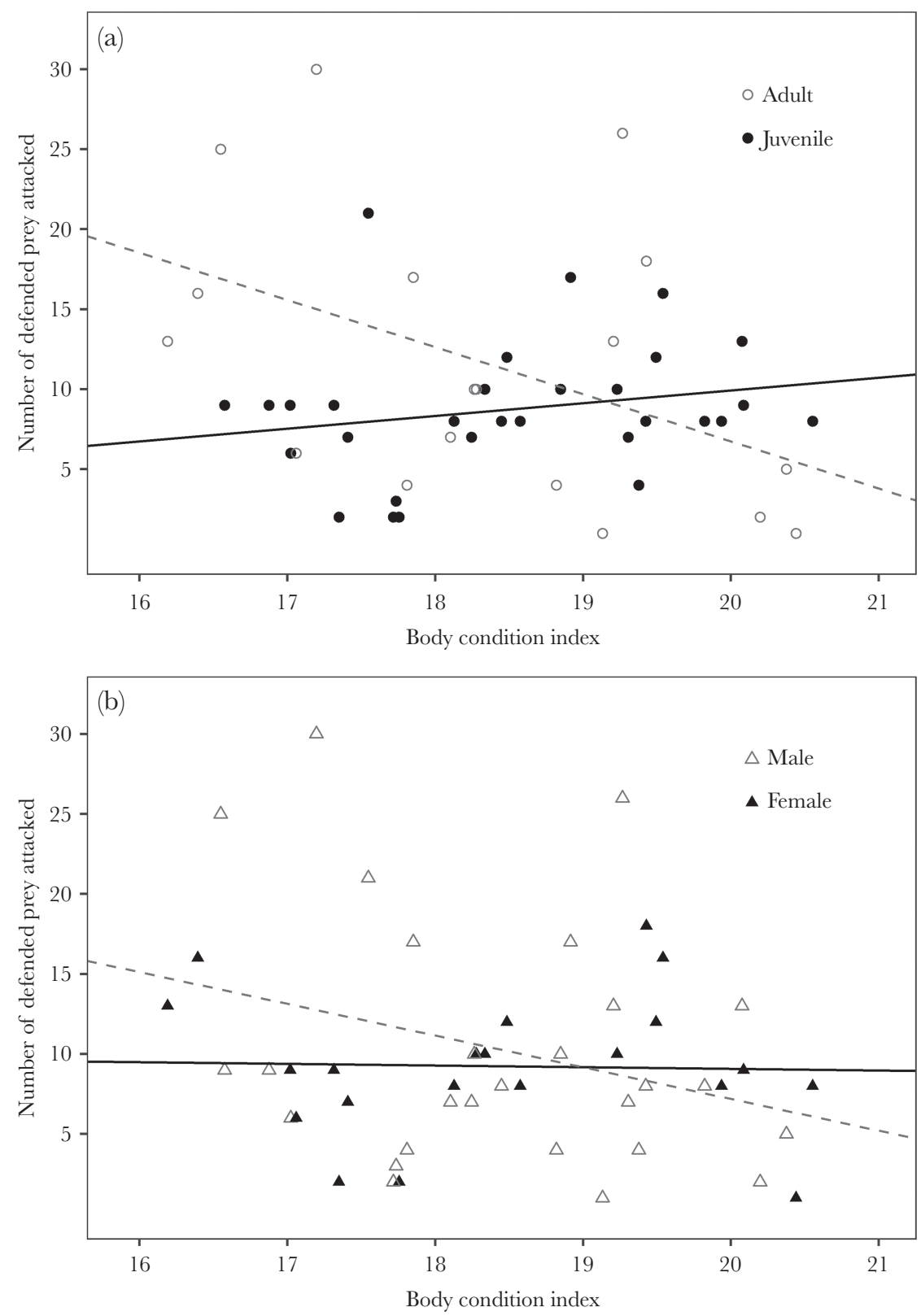

Figure 4

Number of defended prey that birds $(n=48)$ attacked during avoidance learning. (a) Adults (open circles and the dashed line) attacked more defended prey when their body condition was low, whereas there was no effect of body condition in juveniles (filled circles and the solid line). (b) Males (open triangles and the dashed line) attacked more defended prey when their body condition was low, whereas there was no effect of body condition in females (filled triangles and the solid line).

studies are required to understand its effects on prey rejection and avoidance learning.

Disentangling the effects of taste and toxicity on predators' foraging decisions is often difficult. Stronger taste might not be always linked to a higher toxin concentration (Ruxton and Kennedy 2006; Holen 2013; Nissim et al. 2017; Marples et al. 2018) or vice versa (Lawrence et al. 2019), and predator species may vary in what they find unpalatable (Rojas et al. 2017). Our study indicates that after detecting bitter taste, birds make their foraging decisions based on the post-ingestive feedback of consuming toxins. This distinction between distastefulness and unprofitability was recently highlighted by Marples et al. (2018) who suggested that these two prey qualities should be treated as separate phenomena, with predators avoiding unprofitable (but not only distasteful) prey. Our results support the idea that prey toxicity is important for predator learning (Brower 1969; Skelhorn and Rowe 2010), and defense based solely on distastefulness may not protect prey (but see Skelhorn and Rowe 2009). To investigate the effects of taste and toxicity separately, further studies should aim to manipulate predators' ability to taste. An antagonist for chicken taste receptors was recently described (Dey et al. 2017), making taste perception manipulation possible, similar to studies in which birds' sense of smell is blocked to test how olfactory cues influence their navigation (Gagliardo et al. 2013). Further work is also needed to investigate the effects of taste on learning about weaker or more variable prey defenses (Ihalainen et al. 2007, 2008). In our experiment, the concentration of chloroquine 
diphosphate solution was very high to ensure that birds acquired avoidance to defended prey. Even though high doses of quinine can be emetic to birds (Alcock 1970), we do not know how costly it is to ingest at lower concentrations, and our pilot tests suggested that birds did not avoid prey with weaker defense. However, the use of high chloroquine concentration in the avoidance learning test means that even less sensitive birds were likely to detect prey unpalatability easily, which could explain why we did not find a correlation between the taste response threshold and learning.

In conclusion, our study suggests that great tits differ in their responses to bitter taste, but this does not influence the number of defended prey that they are willing to consume. This indicates that other factors, such as visual cues, might be more important than taste for influencing predators' initial decision to consume prey (Marples et al. 1994; Ihalainen et al. 2007), whereas prey toxicity and its physiological effects might drive later foraging behavior (Skelhorn et al. 2016). Nevertheless, the ability to detect bitter taste might be important when predators are sampling prey with weaker chemical defenses or when defenses are more variable, which can increase the risk of ingesting toxins (Skelhorn and Rowe 2005; Barnett et al. 2014). Furthermore, predators can gather social information about prey unpalatability by observing the disgust responses of other predators (Mason and Reidinger 1982; Johnston et al. 1998; Skelhorn 2011; Thorogood et al. 2018; Hämäläinen et al. 2019a). Our study indicates that individuals vary in how likely they are to show these responses, which could create heterogeneity in social information that is available for observing predators. For example, more sensitive individuals might have a larger role in providing information for others, and this could influence how social information spreads in the predator population. We did not quantify the strength of aversive response in our study, but this is also likely to vary among individuals, with some birds performing more beak wiping and head shaking than others. Stronger responses might be a more salient signal of unpalatability for the observing individuals (Skelhorn 2011), but how the strength of the aversive response influences social avoidance learning remains untested.

\section{SUPPLEMENTARY MATERIAL}

Supplementary material can be found at Behavioral Ecology online.

\section{FUNDING}

This work was supported by the Academy of Finland (grant number 284666). L.H. was supported by the Finnish Cultural Foundation and Emil Aaltonen Foundation. R.T. is supported by an Independent Research Fellowship from the Natural Environment Research Council UK (grant number NE/K00929X/1) and a start-up grant from the Helsinki Institute of Life Science (HiLIFE), University of Helsinki. H.M.R. was supported by a research fellowship from the Institute of Zoology, Zoological Society of London, and is currently supported by the Max Planck Society.

\section{CONFLICT OF INTEREST}

We have no conflict of interest to declare.

We are grateful to Helinä Nisu for taking care of the birds, the staff at Konnevesi Research Station for providing facilities for the experiment, Victoria Franks for providing illustrations, and Robert Burriss for his comments on the manuscript. We also thank two anonymous referees for helpful comments. Wild birds were used with permission from the Central
Finland Centre for Economic Development, Transport and Environment and license from the National Animal Experiment Board (ESAVI/9114/ 04.10.07/2014) and the Central Finland Regional Environmental Centre (VARELY/294/2015).

Data accessibility: Analyses reported in this article can be reproduced using the data provided by Hämäläinen et al. (2019b).

Handling editor: Marc Naguib

\section{REFERENCES}

Alatalo RV, Mappes J. 1996. Tracking the evolution of warning signals. Nature. 382:708-710.

Alcock J. 1970. Punishment levels and the response of black-capped chickadees (Parus atricapillus) to three kinds of artificial seeds. Anim Behav. 18:592-599.

Barnett CA, Bateson M, Rowe C. 2007. State-dependent decision making: educated predators strategically trade off the costs and benefits of consuming aposematic prey. Behav Ecol. 18:645-651.

Barnett CA, Bateson M, Rowe C. 2014. Better the devil you know: avian predators find variation in prey toxicity aversive. Biol Lett. 10:20140533.

Barnett CA, Skelhorn J, Bateson M, Rowe C. 2012. Educated predators make strategic decisions to eat defended prey according to their toxin content. Behav Ecol. 23:418-424.

Bates D, Mächler M, Bolker B, Walker S. 2015. Fitting linear mixed-effects models using lme4.J Stat Softw. 67:1-48.

Beckmann C, Shine R. 2011. Toad's tongue for breakfast: exploitation of a novel prey type, the invasive cane toad, by scavenging raptors in tropical Australia. Biol Invasions. 13:1447-1455.

Behrens M, Korsching SI, Meyerhof W. 2014. Tuning properties of avian and frog bitter taste receptors dynamically fit gene repertoire sizes. Mol Biol Evol. 31:3216-3227.

Behrens M, Meyerhof W. 2013. Bitter taste receptor research comes of age: from characterization to modulation of TAS2Rs. Semin Cell Dev Biol. 24:215-221.

Blum MS. 1981. Chemical defenses of arthropods. New York: Academic Press.

Brodie ED III, Brodie ED Jr. 1990. Tetrodotoxin resistance in garter snakes: an evolutionary response of predators to dangerous prey. Evolution. 44:651-659.

Brower LP. 1969. Ecological chemistry. Sci Am. 220:22-29.

Brower LP, Fink LS. 1985. A natural toxic defense system: cardenolides in butterflies versus birds. Ann N Y Acad Sci. 443:171-188.

Bufe B, Breslin PA, Kuhn C, Reed DR, Tharp CD, Slack JP, Kim UK, Drayna D, Meyerhof W. 2005. The molecular basis of individual differences in phenylthiocarbamide and propylthiouracil bitterness perception. Curr Biol. 15:322-327.

Calvert WH, Hedrick LE, Brower LP. 1979. Mortality of the monarch butterfly (Danaus plexippus L.): avian predation at five overwintering sites in Mexico. Science. 204:847-851.

Chandrashekar J, Mueller KL, Hoon MA, Adler E, Feng L, Guo W, Zuker CS, Ryba NJ. 2000. T2Rs function as bitter taste receptors. Cell. 100:703-711.

Chatelain M, Halpin CG, Rowe C. 2013. Ambient temperature influences birds' decisions to eat toxic prey. Anim Behav. 86:733-740.

Cowart BJ, Yokomukai Y, Beauchamp GK. 1994. Bitter taste in aging: compound-specific decline in sensitivity. Physiol Behav. 56:1237-1241.

Cuthill I, Witter M, Clarke L. 1992. The function of bill-wiping. Anim Behav. 43:103-115.

Davis JK, Lowman JJ, Thomas PJ, ten Hallers BF, Koriabine M, Huynh LY, Maney DL, de Jong PJ, Martin CL, Thomas JW; NISC Comparative Sequencing Program. 2010. Evolution of a bitter taste receptor gene cluster in a New World sparrow. Genome Biol Evol. 2:358-370.

Dey B, Kawabata F, Kawabata Y, Yoshida Y, Nishimura S, Tabata S. 2017. Identification of functional bitter taste receptors and their antagonist in chickens. Biochem Biophys Res Commun. 482:693-699.

Endler JA, Mappes J. 2004. Predator mixes and the conspicuousness of aposematic signals. Am Nat. 163:532-547.

Exnerová A, Landová E, Štys P, Fuchs R, Prokopová M, Cehláriková P. 2003. Reactions of passerine birds to aposematic and non-aposematic firebugs (Pyrrhocoris apterus; Heteroptera). Biol J Linn Soc. 78:517-525. 
Fink LS, Brower LP. 1981. Birds can overcome the cardenolide defence of monarch butterflies in Mexico. Nature. 291:67-70.

Fink LS, Brower LP, Waide RB, Spitzer PR. 1983. Overwintering monarch butterflies as food for insectivorous birds in Mexico. Biotropica. 15:151-153.

Fukunaga A, Uematsu H, Sugimoto K. 2005. Influences of aging on taste perception and oral somatic sensation. J Gerontol A Biol Sci Med Sci. 60:109-113.

Gagliardo A, Bried J, Lambardi P, Luschi P, Wikelski M, Bonadonna F. 2013. Oceanic navigation in Cory's shearwaters: evidence for a crucial role of olfactory cues for homing after displacement. J Exp Biol. 216:2798-2805.

Garcia-Bailo B, Toguri C, Eny KM, El-Sohemy A. 2009. Genetic variation in taste and its influence on food selection. OMICS. 13:69-80.

Glendinning JI. 1994. Is the bitter rejection response always adaptive? Physiol Behav. 56:1217-1227.

Glendinning JI, Brower LP, Montgomery CA. 1990. Responses of three mouse species to deterrent chemicals in the monarch butterfly. I. Taste and toxicity tests using artificial diets laced with digitoxin or monocrotaline. Chemoecology. 3-4:114-123.

Halpin CG, Skelhorn J, Rowe C. 2012. The relationship between sympatric defended species depends upon predators' discriminatory behaviour. PLoS One. 7:e44895.

Halpin CG, Skelhorn J, Rowe C. 2014. Increased predation of nutrientenriched aposematic prey. Proc Biol Sci. 281:20133255.

Hämäläinen L, Mappes J, Rowland HM, Thorogood R. 2019a. Social information use about novel aposematic prey is not influenced by a predator's previous experience with toxins. Funct Ecol. 33:1982-1992.

Hämäläinen L, Mappes J, Thorogood R, Valkonen JK, Karttunen K, Salmi T, Rowland HM. 2019b. Data from: predators' consumption of unpalatable prey does not vary as a function of bitter taste perception. Dryad Digital Repository. https://doi.org/10.5061/dryad.h44j0zpfj

Holen ØН. 2013. Disentangling taste and toxicity in aposematic prey. Proc Biol Sci. 280:20122588.

Ihalainen E, Lindström L, Mappes J. 2007. Investigating Müllerian mimicry: predator learning and variation in prey defences. J Evol Biol. 20:780-791.

Ihalainen E, Lindström L, Mappes J, Puolakainen S. 2008. Butterfly effects in mimicry? Unpredictable relationship between Müllerian co-mimics. Behav Ecol Sociobiol. 62:1267-1276.

Johnston ANB, Burne THJ, Rose SPR. 1998. Observation learning in dayold chicks using a one-trial passive avoidance learning paradigm. Anim Behav. 56:1347-1353.

Lawrence JP, Rojas B, Fouquet A, Mappes J, Blanchette A, Saporito RA, Bosque RJ, Courtois EA, Noonan BP. 2019. Weak warning signals can persist in the absence of gene flow. Proc Natl Acad Sci USA. 116:19037-19045.

Lindemann B. 2001. Receptors and transduction in taste. Nature. 413:219-225

Lipchock SV, Mennella JA, Spielman AI, Reed DR. 2013. Human bitter perception correlates with bitter receptor messenger RNA expression in taste cells. Am J Clin Nutr. 98:1136-1143.

Lipchock SV, Spielman AI, Mennella JA, Mansfield CJ, Hwang LD, Douglas JE, Reed DR. 2017. Caffeine bitterness is related to daily caffeine intake and bitter receptor mRNA abundance in human taste tissue. Perception. 46:245-256.

Longson CG, Joss JMP. 2006. Optimal toxicity in animals: predicting the optimal level of chemical defences. Funct Ecol. 20:731-735.

Majerus MEN, Majerus TMO. 1997. Predation of ladybirds by birds in the wild. Entomol Mon Mag. 133:55-61.

Marples NM, Speed MP, Thomas RJ. 2018. An individual-based profitability spectrum for understanding interactions between predators and their prey. Biol J Linn Soc. 125:1-13.

Marples NM, van Veelen W, Brakefield PM. 1994. The relative importance of colour, taste and smell in the protection of an aposematic insect Coccinella septempunctata. Anim Behav. 48:967-974.

Mason JR, Reidinger RF. 1982. Observational learning of food aversions in red-winged blackbirds (Agelaius phoeniceus). Auk. 99:548-554.
Matson KD, Millam JR, Klasing KC. 2004. Cockatiels (Nymphicus hollandicus) reject very low levels of plant secondary compounds. Appl Anim Behav Sci. 85:141-156.

Naef-Daenzer L, Naef-Daenzer B, Nager RG. 2000. Prey selection and foraging performance of breeding Great Tits Parus major in relation to food availability. J Avian Biol. 31:206-214.

Nissim I, Dagan-Wiener A, Niv MY. 2017. The taste of toxicity: a quantitative analysis of bitter and toxic molecules. IUBMB Life. 69:938-946.

Peig J, Green AJ. 2009. New perspectives for estimating body condition from mass/length data: the scaled mass index as an alternative method. Oikos. 118:1883-1891.

Poulton EB. 1890. The colours of animals: their meaning and use especially considered in the case of insects. London: Kegan Paul, Trench, Trübner \& Co.

R Core Team. 2019. R: a language and environment for statistical computing. Vienna (Austria): R Foundation for Statistical Computing.

Reed DR, Zhu G, Breslin PA, Duke FF, Henders AK, Campbell MJ, Montgomery GW, Medland SE, Martin NG, Wright MJ. 2010. The perception of quinine taste intensity is associated with common genetic variants in a bitter receptor cluster on chromosome 12. Hum Mol Genet. 19:4278-4285.

Rojas B, Burdfield-Steel E, Pakkanen H, Suisto K, Maczka M, Schulz S, Mappes J. 2017. How to fight multiple enemies: target-specific chemical defences in an aposematic moth. Proc Biol Sci. 284:20171424.

Rowland HM, Parker MR, Jiang P, Reed DR, Beauchamp GK. 2015. Comparative taste biology with special focus on birds and reptiles. In: Doty RL, editor. Handbook of olfaction and gustation New York: Wiley. p. $957-982$.

Ruxton GD, Kennedy MW. 2006. Peppers and poisons: the evolutionary ecology of bad taste. J Anim Ecol. 75:1224-1226.

Ruxton GD, Sherratt TN, Speed MP. 2018. Avoiding attack. Evolutionary ecology of crypsis, warning signals and mimicry. 2nd ed. Oxford: Oxford University Press.

Sandre SL, Stevens M, Mappes J. 2010. The effect of predator appetite, prey warning coloration and luminance on predator foraging decisions. Behaviour. 147:1121-1143.

Sherratt TN. 2003. State-dependent risk-taking by predators in systems with defended prey. Oikos. 103:93-100.

Shin YK, Cong WN, Cai H, Kim W, Maudsley S, Egan JM, Martin B. 2012. Age-related changes in mouse taste bud morphology, hormone expression, and taste responsivity. J Gerontol A Biol Sci Med Sci. 67:336-344.

Skelhorn J. 2011. Colour biases are a question of conspecifics taste. Anim Behav. 81:825-829

Skelhorn J, Halpin CG, Rowe C. 2016. Learning about aposematic prey. Behav Ecol. 27:955-964.

Skelhorn J, Rowe C. 2005. Tasting the difference: do multiple defence chemicals interact in Müllerian mimicry? Proc Biol Sci. 272:339-345.

Skelhorn J, Rowe C. 2006. Taste-rejection by predators and the evolution of unpalatability in prey. Behav Ecol Sociobiol. 60:550-555.

Skelhorn J, Rowe C. 2007. Predators' toxin burdens influence their strategic decisions to eat toxic prey. Curr Biol. 17:1479-1483.

Skelhorn J, Rowe G. 2009. Distastefulness as an antipredator defence strategy. Anim Behav. 78:761-766.

Skelhorn J, Rowe C. 2010. Birds learn to use distastefulness as a signal of toxicity. Proc Biol Sci. 277:1729-1734.

Stoffel MA, Nakagawa S, Schielzeth H. 2017. rptR: repeatability estimation and variance decomposition by generalized linear mixed-effects models. Methods Ecol Evol. 8:1639-1644.

Su Y, Li D, Gaur U, Wang Y, Wu N, Chen B, Xu Z, Yin H, Hu Y, Zhu Q. 2016. Genetic diversity of bitter taste receptor gene family in Sichuan domestic and Tibetan chicken populations. J Genet. 95:675-681.

Thorogood R, Kokko H, Mappes J. 2018. Social transmission of avoidance among predators facilitates the spread of novel prey. Nat Ecol Evol. 2:254-261.

Wang K, Zhao H. 2015. Birds generally carry a small repertoire of bitter taste receptor genes. Genome Biol Evol. 7:2705-2715.

Warren RP, Vince MA. 1963. Taste discrimination in the great tit (Parus major). J Comp Physiol Psychol. 56:910-913.

Zhao H, Li J, Zhang J. 2015. Molecular evidence for the loss of three basic tastes in penguins. Curr Biol. 25:R141-R142. 